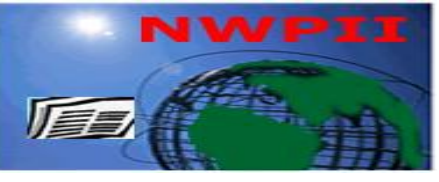

American Journal of Biomedical Sciences

ISSN: 1937-9080

nwpii.com/ajbms

\title{
Bacteriological Identification among Patients Attending Intensive Care Unit at Nemba District Hospital
}

\author{
Callixte Yadufashije ${ }^{1}$, Thierry Habyarimana ${ }^{1}$, John Karemera ${ }^{2}$, Cedrick Izere ${ }^{2}$, \\ Monique Mukundente ${ }^{3}$, Ange Yvette Uwitonze ${ }^{2}$
}

\begin{abstract}
${ }^{1} \mathrm{PhD}$, Department of Biomedical Laboratory sciences, INES-Ruhengeri, Rwanda
${ }^{2} \mathrm{MSc}$, Department of Biomedical Laboratory sciences, INES-Ruhengeri, Rwanda

${ }^{3} \mathrm{BSc}$, Department of Biomedical Laboratory sciences, INES-Ruhengeri, Rwanda

"Corresponding Author
\end{abstract}

Dr. Callixte Yadufashije

Department of Biomedical Laboratory

INES-Ruhengeri

Rwanda

Email: cyadufashije@ines.ac.rw, cyadufashije@gmail.com

Received:01 January 2019; | Revised:07 January 2019; | Accepted: 04 June 2019

\section{Abstract}

Background: This study entitled bacteriological identification among patients attending intensive care unit at Nemba District Hospital was conducted in bacteriology unit of Nemba District Hospital. The range between $5 \%$ and $15 \%$ of hospital patients in an intensive care unit is 5-10 times more likely acquiring a nosocomial infection.

Objectives: The study was objectively assessed bacterial infections among patients attending ICU and predominant bacteria were mentioned. Both sensitivity and resistance of antibiotics were performed to know the better treatment for infections in ICU patients.

Methods: The samples were collected from intensive care unit services and phlebotomy of Nemba District Hospital and tested in laboratory in the service of bacteriology unit and bacteria were identified by means of a gram stain, biochemical tests and culture.

Results and conclusion: Findings of conducted study showed that the predominant bacteria in intensive care unit. Among predominant bacteria identified include Staphylococcus Aureus (37\%), Escherichia coli (24\%), Salmonella typhi (35\%), Pseudomonas aeruginosa (1\%) and Klebsiella pneumoniae (3\%) Among the antibiotic susceptibility test, Staphylococcus Aureus showed the total resistant on penicillin while tetracycline showed to have the highest sensitivity. Salmonella typhi showed resistance on amoxicillin $(100 \%)$, Escherichia coli showed the total resistant on gentamicin $(100 \%)$.

Hospitalized patients in intensive care unit are at risk of acquiring Nosocomial infections due to the presence of mentioned bacteria during this study. The big issue is that these infections resist to antibiotics used in treatment according to results of the study. Health care workers in ICU should improve hygiene to control hospital acquired infections and much attention should be done during diagnosis to improve treatment of patients. 
Keywords: Bacteria, Antibiotics, Infection, Patient

\section{Introduction}

Intensive care unit (ICU)-acquired infections are known to be common cause of morbidity and mortality among ICU patients ${ }^{[1]}$. These infections are due to multidrug-resistant (MDR) bacteria and seriously lead to healthcare problem, and a daily challenge among clinicians dealing with diagnosis and treatment of patients ${ }^{[2]}$. Cross-contamination of pathogens among patients of inanimate surfaces around patients in ICU has been clearly identified in outbreaks; contamination can take place either by microorganisms transfer that contaminated health workers' hands or direct patient shedding of microorganisms while performing their task related to patient care and treatment ${ }^{[3]}$.

Infections crossing from patient to another as well as from hospital health workers to patients constructed huge hazards in health care especially in developing world ${ }^{[4]}$. These infections are mostly known to be causes of morbidity and mortality in intensive care unit worldwide. Contamination due to bacteria in hospitals are related directly or indirectly to the use of antibiotics in improper way by number of patients, and when the use of disinfectants ate at low concentrations comparing to the recommended one for purpose of cleaning in different hospitals in both developing and developed countries ${ }^{[5]}$. This improper use of disinfectants creates opportunities of new stains bacteria appearance that resist to current used antibiotics ${ }^{[6]}$.

The most known common nosocomial infections including ventilator-associated pneumonia, urinary tract infections (UTIS) and bloodstream infection ${ }^{[7]}$. The way of how ICU environment is in terms of hygiene and other activities related to patient care build the way of spreading various antimicrobial-resistance pathogens. Both gram native and positive resist to antibiotics and most of them are Staphylococci wide variety of Enterobacteriaceae, Pseudomonas species, Acinetobacter species or Candida species ${ }^{[8]}$.

Despite all effort done by health care setting to reduce the burden of infections in intensive care unit, the rate of these infections continue to be a burden, however, there is no surprise as patient in ICU are at high risk of various infections due to their health state ${ }^{[9]}$. Modern technology in medicine with new treatment technology of organ replacement therapies has been successfully brought solution to some diseases but with second illness complications in ICU. However, these ICU patients are often at risk of infection due to impairing effects of their diseases and therapies on the immune system as well as some operative treatment consequences ${ }^{[10]}$.

Based on Centers for Disease Control and Prevention criteria, infections found or diagnosed in ICU are traditionally categorized in two by means of two ways. The first way is the technique of gram staining in which all microorganisms grouped in either Gram positives or Gram negatives. The second category is the time spent for incubation and this make differences from nosocomial infection community ${ }^{[11]}$. Infection categorization is a very big issue in various infection surveillance, control and management, especially in ICU as most of patient in this service are risky to get second infection ${ }^{[12]}$.

Health setting acquired infection especially in ICU ( nosocomial infection) based on time spent at health setting, and 48 hours are enough to distinguish nosocomial infection from community infections [13]. Clinicians have taken this in consideration and confirmed that infection that can occur after 48 hours of hospital is not considered to be nosocomial or ICU acquired infection ${ }^{[14]}$.

The proposal of classifying infections in ICU basing on atient's knowledge was discussed as can be taken as a new method. It is an approach allowing the distinction between imported, or primary, and secondary carriage of potentially pathogenic micro-organisms (PPMs), in addition to endogenous and exogenous infections ${ }^{[15]}$.

\section{Materials and Methods}

\subsection{Study design and sample collection}

This study was conducted from August to october 2018 and 160 hospitalized patients in 
Nemba District hospital were targeted. inclusion criteria were all patients who diagnosed clinically, have bacterial infection and admitted in internal medicine (IM) and surgery department. The study was carried out using cross section and retrospective method to collect the samples of blood of the patients in tubes of hemoculture in phlebotomy service on intensive care unit service and transferred in laboratory on bacteriology service and using incubator. In intensive care unit also is applied to collect the samples of fluid of patients in sterile specimen container. Sample taken are: blood, urine, pus, stool, swabs. Specimen was collected from ICU department and tested on bacteriology unit of laboratory. All specimens were registered.

\subsection{Bacterial identification techniques}

Different techniques were used for bacterial identification. Bacterial identification techniques used during the study including gram staining for gram positive and gram negative differentiation, catalase test to differentiate staphylococci and streptococcus, coagulase test to differentiate staphylococcus aureus (positive) from coagulase negative staphylococci, MacConkey agar was used to identify enterobacteriaceae, however all sample were incubated in hemoculture automated machine"Bactec" to maintain the growth of bacteria.

\subsection{Antibiotic susceptibility tests}

Antibiotic susceptibility test of bacteria was conducted regarding criteria of clinical and performed laboratory standard institute, using the Kirby-Bauer disc diffusion on Mueller Hinton agar. Isolates were grown in peptone water at 370C turbidity was matched with 0.5 McFarland standards. The placement of various types of antibiotic on culture was taken place on Mueller Hinton agar plate and incubated for $24 \mathrm{~h}$ on $370 \mathrm{C}$. both the sensitivity and resistance were confirmed by means of measuring the diameter of inhibitor zone.

\section{Results}

\subsection{Demographic characteristics of the participants}

Table 1: Shows demographic characteristics of target population. The below table shows age and sex of patients in ICU. Frequency as well as percentages of patients regarding sex and age are mentioned in the table.

Table 1: demographic characteristics of the participant

\begin{tabular}{|c|c|c|}
\hline Ages group & Frequency & Percent \\
\hline between [8-23] & 45 & 28.1 \\
\hline between [24-39] & 61 & 38 \\
\hline between [40-55] & 40 & 25 \\
\hline between[56-71] & 11 & 7 \\
\hline between[72-87] & 3 & 1.9 \\
\hline Total & 160 & 100 \\
\hline \multicolumn{2}{|c|}{} & Gender \\
\hline Male & 67 & 41.9 \\
\hline Female & 93 & 58.1 \\
\hline Total & 160 & 100 \\
\hline
\end{tabular}


3.2 Sample type collected and diagnostic results in Intensive Care Unit

Table 2: Sample taken in ICU and diagnostic result

\begin{tabular}{|c|c|c|c|}
\hline & Frequency & Result & \\
\hline Samples & & Positive & Negative \\
\hline blood sample & $93(58.1 \%)$ & 31 & 62 \\
\hline pus sample & $44(27.5 \%)$ & 26 & 18 \\
\hline urine sample & $15(9.4 \%)$ & 9 & 0 \\
\hline stool sample & $1(0.6 \%)$ & 1 & 3 \\
\hline swab sample & $7(4.4 \%)$ & 4 & $89(55.6 \%)$ \\
\hline Total & $160(100 \%)$ & $71(44.4 \%)$ & \\
\hline
\end{tabular}

\subsection{Microorganisms identification}

The below figure 1 shows the percentage of isolated bacteria in ICU. Isolated bacteria are as follows: Escherichia coli 17 (24\%), Klebsiella pneumoniae $2(2.8 \%)$. Salmonella thpyi $25(35.2 \%)$

followed by Psedomonas aeruginosa $1(1.4 \%)$ and Staphylococcus aureus 26 (36.6\%). Among 5 species of bacteria isolated, 4 were gram negative while one of them was gram positive bacteria.

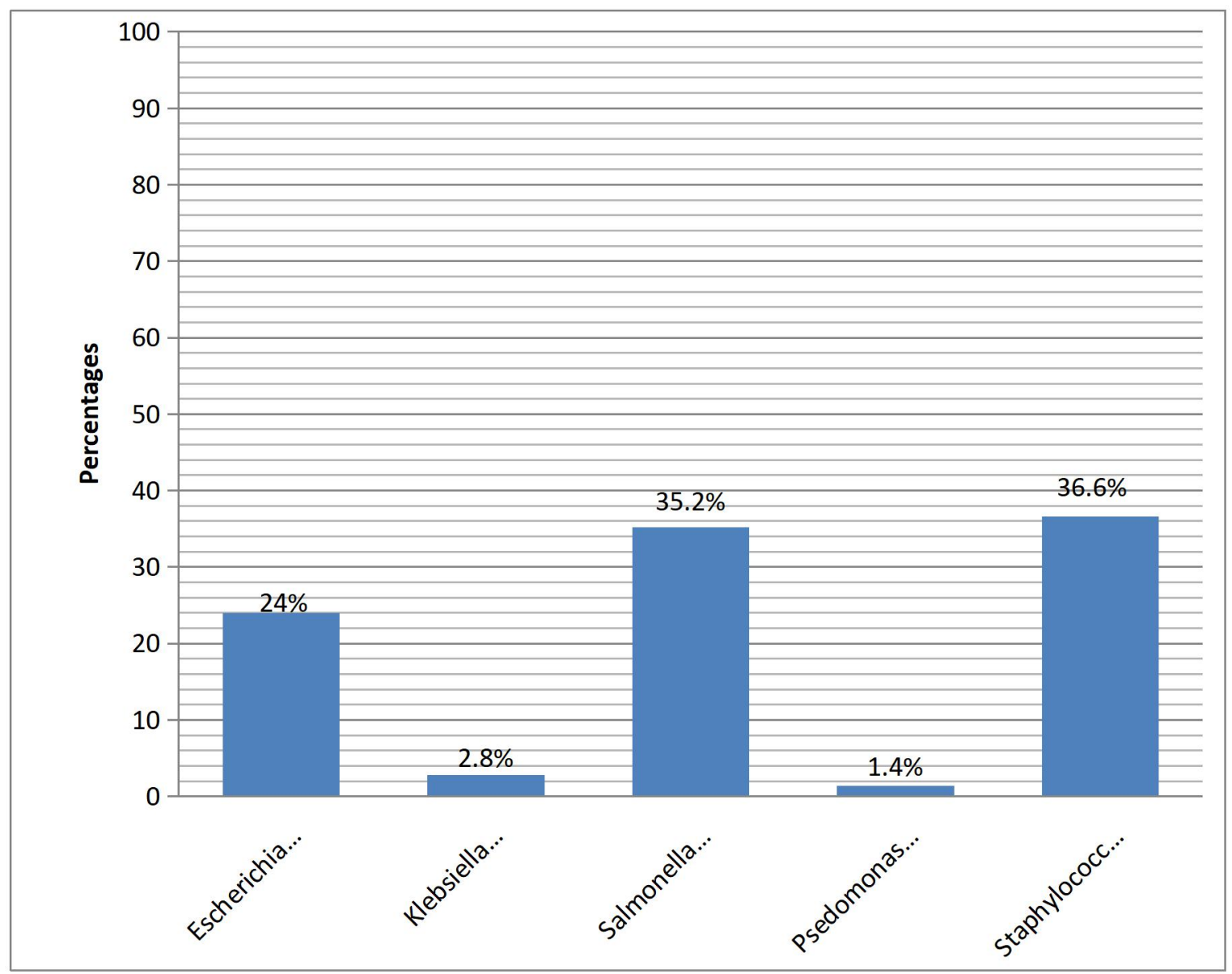

Figure 1: The isolated bacteria and their percentages 


\subsubsection{Antibiotics susceptibility tests of Staphylococcus aureus}

Both sensitivity and resistant rate of staphylococcus aureus were shown using various antibiotics. Tetracycline, Oxacillin, penicillin and Erythromycin are antibiotics used for antibiotics susceptibility test of staphylococcus aureus. Staphylococcus aureus isolated showed the total resistant on penicillin $26(100 \%)$ and moderate on

both erythromycin 24 (92\%) and Oxacillin 13 (50\%) while tetracycline $20(77 \%)$ showed the highest sensitivity. The level of sensitivity and resistance shows the right antibiotics to kill Staphylococcus aureus. In treatment of infection caused by Staphylococcus Aureus Tetracycline can be used as the first antibiotic for disease treatment. Figure2.

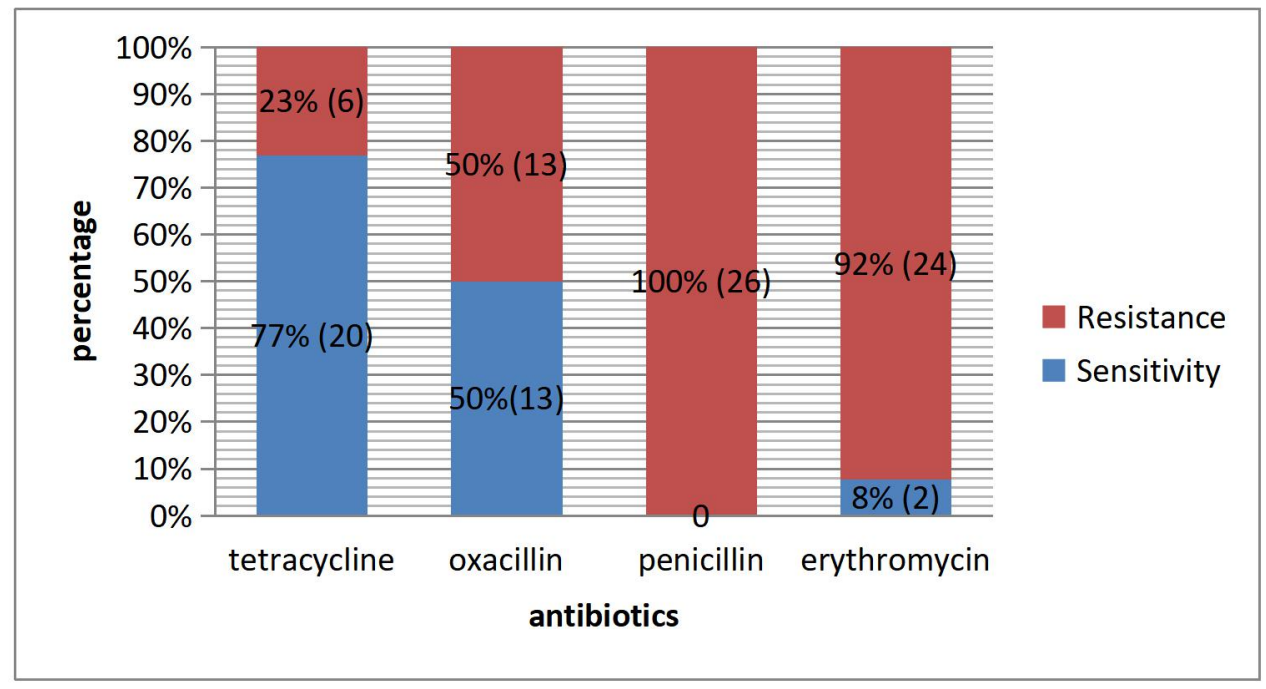

Figure 2: antibiotic types test of Staphylococcus aureus

\subsubsection{Antibiotics susceptibility test of Salmonella typhi}

The antibiotics susceptibility test used for isolate salmonella thpyi including Imipenem, ciprofloxacin, cefotaxime and amoxicillin. It has been shown that Salmonella thpyi isolate totally resist to amoxicillin $25(100 \%)$ and moderately resist to ciprofloxacin $15(60 \%)$ and cefotaxime 13
(52\%) while Imipenem 17 (68\%) showed sensitive. By strict analysis more other drugs are needed to treat infections related to Salmonella typhi level of resistance to be high. However, Imipenem can be used considering the result of this study. Figure 3.

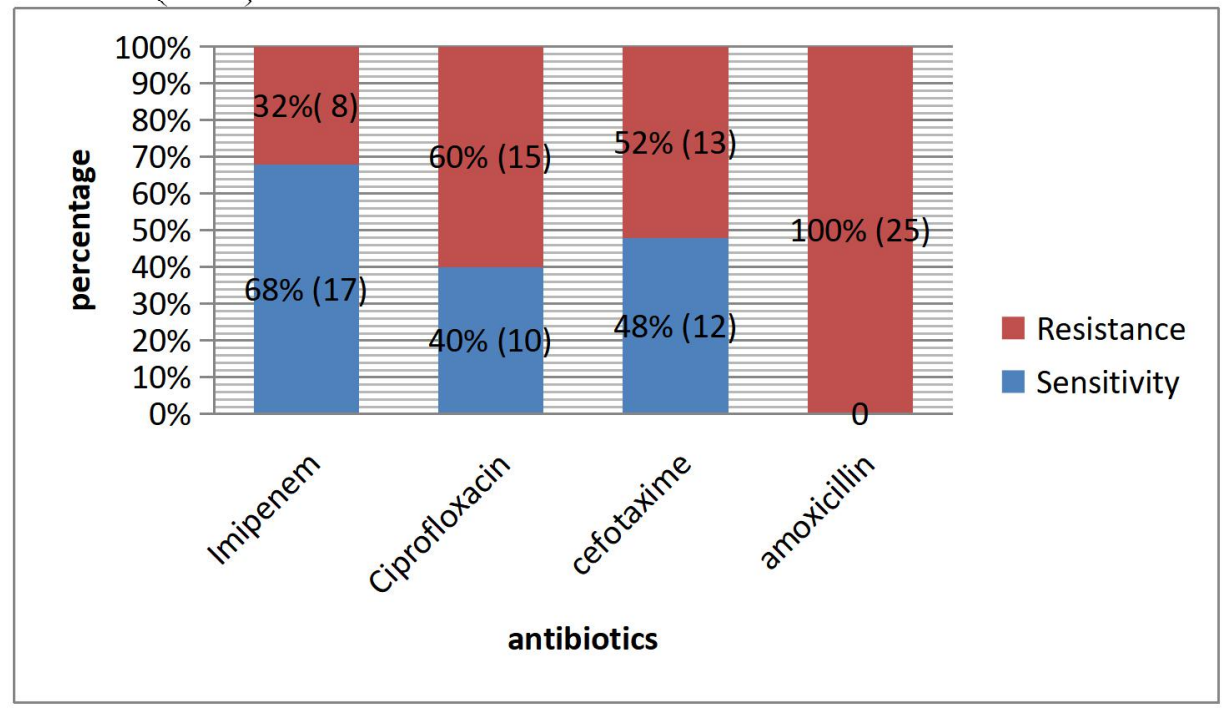

Figure 3: antibiotic types test on Salmonella typhi 


\subsubsection{Antibiotics susceptibility test of Escherichia}

coli

Gentamicin, Imipenem, chloremphenicol and ceftazidime are shown on figure below where the rate of sensitivity and resistant were assessed.

Gentamicin, imipenem, chloremphenicol and ceftazidime used for antibiotics test of Escherichia coli. Escherichia coli isolated showed totality of resisting on on Gentamicin $17(100 \%)$ moderate on ceftazidime 9 (53\%) and chloremphenicol $8(47 \%)$ and sensitivity high on imipenem 16 (94.1\%). Figure4.

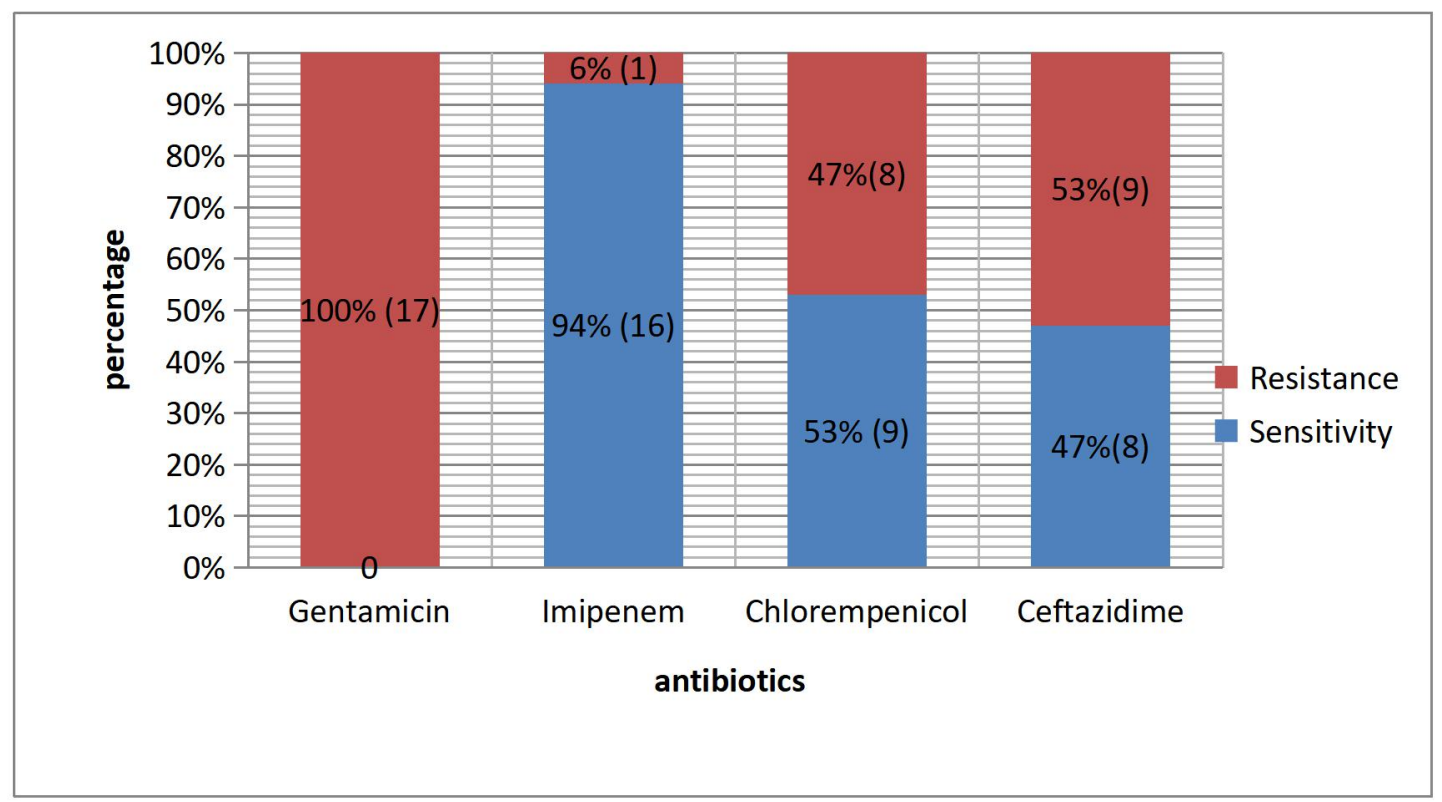

Figure 4: antibiotic types test on Escherichia coli

The very low percentage of the two microorganisms; klebsiella pneumoniae, and Psedomonas aeruginosis were also isolated, however, Psedomonas aeruginosis was seen in swab and klebsiella thpyi was seen in blood specimen. Klebsiella pneumoniae was seen to be resistant to to gentamicin, tetracycline, and cefotaxime with high sensitivity to penicillin. Psedomonas aeruginosa was resistant to Imipenem and erythromycin but sensitive to cefotaxime.

\section{Discussion of results}

\subsection{Predominant infecting bacteria in ICU at Nemba District Hospital}

The study was carried out for identifying common bacteria in patients of Intensive Care Unit at Nemba District Hospital. As shown on the Table2, samples including urine, swab, pus, blood, and stool were taken for different techniques of bacterial identification. The results of this study, the total of 160 patients were tested, 67(41.9\%) were male and 93(58.1\%) were female. Female occupied a great number of patients comparing to male. Another study conducted in India showed the high prevalence of UTI in females (73.57\%) comparing to males whose prevalence was $(35.14 \%)$ and this study is correlated with other studies that show the high prevalence of infection in ICU for females comparing to males [16]. High prevalence of infections were seen among women in ICU, and this is due to susceptibility of women compared to men. It is better known that most of women that are in ICU are those with pregnancy, birth and perinatal complications, which is really a factor causing women to be majority in Intensive Care Unit. The main sample corrected in ICU was blood sample, but the results showed that people with blood samples are low risked compared to others considering percentages of positive results. Patients with pus and urine samples in ICU are at high risk of infections compared to others. This due to kinds of diseases that favors second infections. Pus are mostly taken for people with wound infections and these infections easily infect the patient. Around $59 \%$ of all diagnosed patient with pus sample were 
infected which show high risk of infections among these group of patients. Patients with urine sample also showed high risk of infections, and it usually known that urine are good medium for microorganism growth. It was seen that $60 \%$ of patients diagnosed with urine sample were infected and this a proof showing that urine harbors simply microorganisms and grow. It should be understood that patients in ICU with these kinds of infections, should be hygienic to control second infections.

Predominant bacteria in this study were identified in ICU, both gram negative and gram positive were shown with their percentages on Figure1. The entire prevalence of isolated gram positives was $71(44.4 \%)$ while prevalence for gram negatives was $89(55.6 \%)$. Among gram positives isolated including Staphylococcus aureus with 26 (36.6\%) while isolated gram negative bacteria were Escherichia coli 17 (24\%), salmonella thpyi 25 (35.2\%), klebsiella pneumoniae $2(2.8 \%)$ and Pseudomonas aeruginosa $1(1.4 \%)$. The similar study was conducted in Iraq by Nasser et al., (2013), where 68 of pure colony isolated were identified including $24(35.29 \%)$ gram positive bacterial isolates and 44 (64.71\%) of gram negative bacterial isolate. Another study carried out in Iran by Hassanzadeh \& Hadi (2009) the gram negative $37(4.6 \%)$ bacteria were significantly more involved infections compared to gram positive bacteria 9 $(10.9 \%)^{[9-16]}$. Looking at number of conducted studies in ICU, gram negatives are more prevalent than gram positives, researchers and difference scientists should wonder on causes. A part from deep analysis and identification of predominant bacteria, Staphylococcus aureus was found to be highest prevalent compared to others. These bacteria are known to be among human microbiota and mostly reside on human skin and upper respiratory tract. The results of this study shows that Staphylococcus aureus was mostly found in pus samples and swab samples. The reason of positive test in these sample should be understood, Staphylococcus aureus as microbiota, is known to be opportunistic pathogen in case of immune suppression. Thus serious of follow up should be done during patients staying in ICU with the risk of being infected with Staphylococcus aureus. Staphylococcus aureus is known to cause nosocomial infection and the cause was explained above. Taking care of patients with much hygiene, and avoiding simple contacts of them will reduce the spread of these kind of infection in ICU. The second bacteria dominated is Escherichia Coli, this bacterium lives in environment, and in lower intestines of warm blooded animals. Actually this bacterium leaves move from the host' $\mathrm{s}$ fecal flora to the urogenital tract and cause UTI. This is a justification of the the high presence of E. Coli in urine samples according to the results of this studies. It can be a cause of other infections but mostly known to cause UTI. Thus, most women with UTI should pay attention during their stay in ICU because E. Coli can aggravate the situation and leads to second complications. Another predominant bacterium was Salmonella typhus. This bacterium is known to infect blood and intestinal tract. During this study it was seen mostly in blood samples which show its pathogenicity through blood. Poor hygiene of water facilitates the spread of infections. ICU is a place with many risk to patients, serious control should be done to avoid second infection as well as nosocomial infections.

\subsection{Antibiotic susceptibility test of isolated bacteria}

Frequently isolates of staphylococcus aureus were 26 as presented on Figure2. The antibiotics susceptibility test isolated on staphylococcus aureus, is that it was totally resistant to penicillin $26(100 \%)$, it also showed the highest sensitivity to erythromycin $24(92 \%)$ and while tetracycline 20 (77\%) and moderate sensitivity Oxacillin 13 (50\%). In treatment of infection due to Staphylococcus aureus, the results of the study show that penicillin is not the correct drug to treat Staphylococcus aureus related infection at Nemba District Hospital, however, resistant factors can be later studied in other researches. Similar study was carried out in Ethiopia where Staphylococcus aureus sensitivity were as follow: Vancomycin (99.6\%), erythromycin $(53.2 \%)$, penicillin $(37.7 \%)$ tetracycline $(30.6 \%)$ of the isolated showed antimicrobial agent ${ }^{[17]}$. The difference is seen comparing these two studies, the conducted study at Nemba District, Staphylococcus aureus showed total resistance to penicillin but has been moderately sensitive at $(37.7 \%)$ in this study conducted in Ethiopia. Number of factors contribute to antibiotic resistance and should be prevented 
while treating number of infections. However, bacteria of the same species can have different genetic components, which can also influence resistance in the same species of bacteria. ICU patients mostly suffer from nosocomial infections and are not mostly taken in consideration, and this is among factors leading to antibiotic resistance.

According to Figure3, Salmonella thpyi is also among isolated bacteria, and their frequency was 25 . In this study the antibiotic susceptibility test for isolate on salmonella thpyi, showed the total resistance on amoxicillin $25(100 \%)$ and moderately resist on ciprofloxacin $15(60 \%)$ and cefotaxime $13(52 \%)$ while imipenem showed sensitivity on 17 $(68 \%)$. The same study was conducted in Nigeria where Results showed the general resistance to ceftriaxone, cefuroxime, amoxicillin, ampicillin, and ciprofloxacin and augmentin which are the drugs of choice to treat thyroid fever in the area of study. Although, sensitivity was seen to ofloxacin and chloremphenicol, despite stopping these drugs in treatment of thyroid fever in the area ${ }^{[18]}$. The antibiotic susceptibility test on E.Coli isolated whose frequency were 17 showed the total resistance on gentamicin 17(100\%) moderately resist on ceftazidime $9(23 \%)$ and chloremphenicol $8(47 \%)$. The sensitivity was showed on imipenem $16(94.1 \%)$, Figure4. The study conducted in Ethiopia where the highest isolation rate was obtained from urine samples 203(45.5\%). High resistance rate to erythromycin $(89.4 \%)$, amoxicillin $(86.0 \%)$ and tetracycline $(72.6 \%)$ were seen. However, high sensitivity was seen on nitrofurantoin (96.4\%), norflaxocin (90.6\%), gentamicin $(79.6 \%)$ as well as ciprofloxacin. Different Multiple antimicrobial resistances of $74.6 \%$ and the increase of resistance rates to all antimicrobials except ciprofloxacin were kept ${ }^{[19]}$.

Antibiotic resistance was found to be greater than sensitivity in all cases of test conducted during this study. It is understandable, treating second infection can be very difficult and increase resistance of bacteria to existing antibiotics. The resistance increased basing on factors that favor the bacteria to infect the patient. Staph. Aureus is most resistant bacteria and is known to be predominant to cause nosocomial infections especially in skin and soft tissue due to its location in human body. In ICU while treating some infections, thinking on second infections may be thought due to exposure of patients.

\subsection{Limitation}

The study was conducted at Nemba district hospital to identify common bacteria in ICU; however, a little sample has taken due to limitation of budget to work with all hospitals in Northern Province. The second limitation is that only Nemba district hospital has clinical microbiology laboratory with techniques of bacterial identification like bacterial culture and others in Northern Province.

\section{Conclusion and recommendation}

\subsection{Conclusion}

The patients in intensive care units are more susceptible to nosocomial infections. They are frequently resistant to various used antibiotics; the predominant infecting bacteria in intensive care unit were staphylococcus aureus which is a gram positive bacteria, salmonella thpyi and Escherichia coli which are gram negative bacteria and showed a high resistance to number of antibiotics used during this study. The high increase in resistance of microbes to previous and recent antibiotics is a factor for health facilities to control the spread of infections in terms of improving treatments system as well as providing hygiene to health setting' $\mathrm{s}$ environments and infrastructures.

\subsection{Recommendation}

The following recommendations were addressed to:

The ministry of health in collaboration with researchers should plan researches related to antibiotic susceptibility to know if used antibiotics are effective to treat infections in ICU.

Health education should be provided to the public in terms of using given antibiotics for treatment in a correct way.

Hospitals should improve hygiene and use effective disinfectant.

\section{Acknowledgement}

Grateful thanks to Nemba district hospital staff to accept availing data and laboratory for us to reach results of this study. We do thank also 
academic and research directorate of Ruhengeri institute of higher education (INES-Ruhengeri) to give us time and encouragement while conducting this study.

\section{References}

1 Van Saene, H. K., Silvestri L., de laCal, M. A. Infection Control in the Intensive Care Unit. 2nd ed. Springer; 2005

2 Singh-Naz N, Sprague BM, Patel KM, Pollack MM. Risk factors for nosocomial infection in critically ill children: a prospective cohort study. Crit Care Med 1996; 24(5): 875-878

3 Otter JA, Yezli S, French GL. The role played by contaminated surfaces in the transmission of nosocomial pathogens. Infect Control Hosp Epidemiol 2011; 32(7): 687-699 DOI: 10.1086/660363

4 Chetchotisakd P, Phelps CL, Hartstein AI. Assessment of bacterial cross-transmission as a cause of infections in patients in intensive care units. Clin Infect Dis 1994; 18(6): 929-937

5 Dancer SJ. Importance of the environment in meticillin-resistant Staphylococcus aureus acquisition: the case for hospital cleaning. Lancet Infect Dis 2008; 8(2): 101-113 [PMID: $17974481 \quad$ DOI: $\underline{10.1016 / S 1473-}$ 3099(07)70241-4]

6 Davison HC, Low JC, Woolhouse ME. What is antibiotic resistance and how can we measure it? Trends Microbiol 2000; 8(12): 554-559

7 Agaba P, Tumukunde J, Tindimwebwa JVB, Kwizera A. Nosocomial bacterial infections and their antimicrobial susceptibility patterns among patients in Ugandan intensive care units: a cross sectional study. BMC Res Notes 2017; 10(1): 349 DOI: $\underline{10.1186 / \mathrm{s} 13104-017-2695-5}$

8 Fridkin SK. Increasing prevalence of antimicrobial resistance in intensive care units. Crit Care Med 2001; 29(4 Suppl): N64-68

9 Hassanzadeh P, Motamedifar M, Hadi N. Prevalent bacterial infections in intensive care units of Shiraz University of medical sciences teaching hospitals, Shiraz, Iran. Jpn J Infect Dis 2009; 62(4): 249-253 [PMID: 19628899]

10 Pihlstrom, B. L., Michalowicz, B. S., Johnson, N. W. Periodontal diseases. The Lancet, 2005, 366 (9499), 1809-1820.
11 Murray AE, Chambers JJ, van Saene HK. Infections in patients requiring ventilation in intensive care: application of a new classification. Clin Microbiol Infect 1998; 4(2): 94-99 [PMID: 11864293]

12 Weil MH, Tang W. From intensive care to critical care medicine: a historical perspective. Am J Respir Crit Care Med 2011; 183(11): 1451-1453 DOI: $10.1164 /$ rccm.201008$1341 \mathrm{OE}$

13 Askarian M, Gooran NR. National nosocomial infection surveillance system-based study in Iran: additional hospital stay attributable to nosocomial infections. Am J Infect Control 2003; 31(8): 465-468 [PMID: 14647108]

14 Urrea M, Pons M, Serra M, Latorre C, Palomeque A. Prospective incidence study of nosocomial infections in a pediatric intensive care unit. Pediatr Infect Dis J 2003; 22(6): 490-494

DOI: 10.1097/01.inf.0000069758.00079.d3

15 Khan , H. ,Ahmad , A. , Mehboob, R. Nosocomial infections and their control strategies;Asian Pac J Trop Biomed, 2015, 5 (7), 509-514.

16 Prakash D, Saxena RS. Distribution and antimicrobial susceptibility pattern of bacterial pathogens causing urinary tract infection in urban community of meerut city, India. ISRN Microbiol 2013; 2013: 749629 DOI: $10.1155 / 2013 / 749629$

17 Gizachew, M., Abdella, H., \& Tiruneh, M. Antimicrobial Susceptibility Patterns of Staphylococcus aureus at the University of Gondar Tertiary Hospital, Northwest Ethiopia: A Retrospective Cross Sectional Study.Journal of Bacteriology \& Parasitology, 2015, 6 (3), 1-7.

18 Adabara NU, Ezugwu BU, Momojimoh A, Madzu A, Hashiimu Z, Damisa D. The Prevalence and Antibiotic Susceptibility Pattern of Salmonella typhi among Patients Attending a Military Hospital in Minna, Nigeria. Adv Prev Med 2012; 2012: 875419 DOI: $\underline{10.1155 / 2012 / 875419}$

19 Kibret M, Abera B. Antimicrobial susceptibility patterns of E. coli from clinical sources in northeast Ethiopia. Afr Health Sci 2011; 11 Suppl 1: S40-45 PMID: 22135643 